\title{
Pictorial and verbal encoding in a short-term memory task
}

\author{
BARBARA TVERSKY ${ }^{2}$ \\ THE HEBREW UNIVERSITY OF JERUSALEM
}

The present research attempted to manipulate the encoding modality, pictorial or verbal, of schematic faces with well-learned names by manipulating $S$ 's expectations of the way the material was to be used. On every trial, a single name or face was presented, followed by another one; the $S$ was asked to respond "same" if the stimuli had the same name, and "different" otherwise. The majority of second stimuli of any session was either names or faces. It was hypothesized that if $S$ had encoded the first stimulus in the modality of the second, his judgment would be faster than if he had not appropriately encoded the first stimulus. Significantly slower reaction times were obtained to stimulus pairs where the second stimulus modality was infrequent. Further evidence that encoding of the first stimulus was in the frequent second stimulus modality comes from the finding that "different" responses were shorter when the stimuli differed on more than one attribute in the encoding (second stimulus) modality, regardless of the modality of the stimuli. Thus, evidence is presented that not only can verbal material be pictorially encoded (and vice versa), but that whether either verbal or pictorial material is verbally or pictorially encoded depends on $S$ 's anticipation of what he is to do with the material.

A variety of theories of short-term memory maintain that the stimulus, whether visually or aurally presented, is encoded by the $S$ in some acoustic or verbal form within about $1 \mathrm{sec}$ after presentation (Sperling, 1967; Glanzer \& Clark, 1963a). Evidence supporting this proposition derives from correlations of acoustic or linguistic indices with errors in recall or with amount retained. Errors in short-term recall of consonants correlate highly with listening errors for consonants embedded in noise (Conrad, 1964), even with visual presentation and written recall (Wickelgren, 1965a). Lower short-term retention of highly acoustically confusing lists has been found with consonants (Conrad, Baddeley, \& Hull, 1966; Conrad \& Hull, 1964; Wickelgren, 1965c), and with words (Baddeley, 1964, 1966a, b; Conrad, 1963; Dale \& Gregory, 1966), with recognition (Wickelgren, 1966b) as well as with recall. When acoustically similar items precede (Wickelgren, 1966a) or follow (Wickelgren, $1965 \mathrm{~b}$ ) the to-be-remembered items, recall is lower than if the proactive and retroactive items were acoustically different. Furthermore, certain linguistic measures correlate with short-term retention of pictorial as well as verbal stimuli. "Codability" of colors, the main factor emerging from a factor analysis of inter-S and intra-S agreement of color names, length of name, and latency of naming, successfully predicts recognition accuracy and recognition memory for color chips (Brown \& Lenneberg, 1954). A similarly devised codability index for photographs of facial expressions accounts well for recognition memory of the faces (Van de Geer \& Fridja, 1960). Brevity of verbal description has been found to correlate highly with reproductive recall of arrays of simple black or white figures (Glanzer \& Clark, 1963a) and of strings of binary digits (Glanzer \& Clark, 1963b). Finally, inter-S communication accuracy has been found to account well for color memory (Lantz \& Stefflre, 1964). In contrast to these results obtained in short-term memory, little or no evidence for acoustic or verbal encoding is found in very-short-term memory. In the analysis of several thousand errors committed in the partial recall of 4 by 4 arrays of consonants, Rudov (1966) found most errors to be visual in nature, that is, intrusions from the adjacent row or column or visually similar substitutions. In a similar task, Turvey (1967) found no effects of acoustically confusing lists, nor did Glucksberg, Fisher, and Monty (1967), who did find decrements in recall with visually confusing lists. In a task where pairs of letters, capital or small, were presented visually staggered in time and where Ss reported "same" if the letters had the same name or "different" otherwise, Posner and Keele (1967) found that the advantage of physical identity (both letters either capital or small) to the reaction time of a "same" response seemed to disappear when the stimuli were separated by $1 \mathrm{sec}$ or more. This finding suggests that after a 1-sec delay, the first letter has been acoustically encoded.

Recently, data from short-term memory tasks that are not easily accounted for by an acoustic or verbal theory of encoding have been accumulating. Adams and Dijkstra (1966) argued that retention of a motor response, which declined with retention interval but improved with number of reinforced trials, was not verbally mediated because the unfilled retention interval would have allowed rehearsal of the verbally encoded stimulus thereby preventing forgetting, and because $\mathrm{Ss}$, in order to have verbally encoded the motor movements, would have needed verbal labels capable of discriminating graded responses differing by only $4 \mathrm{~cm}$. Posner and Konick (1966) and Posner (1967) similarly maintained that neither retention of a kinesthetic-distance response, which declined with unfilled retention interval, nor retention of a visual-location response, which declined only when the retention interval was filled, was verbally mediated. In the latter case, Ss reported using "images" to remember the stimuli, and a control group of Ss, given exact verbal information, did not perform as well as Ss given the visual information. In a visual search task, where Ss scanned a list of 120 letters for a target letter, the use of acoustically confusing lists produced no decrement in performance, while the use of visually confusing lists hindered performance (Gibson \& Yonas, 1966a; Kaplan, Yonas, \& Shurcliff, 1966; Gibson \& Yonas, 1966b). In the sequential recall of two pairs of digits, one pair presented aurally, the other visually, Margraine (1967) found selective effects of the modality of recall or rehearsal of the first pair on recall of the second pair. Recall of visually presented material was more damaged by written interpolated activity, while recall of aurally presented material was more damaged by spoken interpolated activity. Rubin (personal communication, 1967) obtained the same result by presenting word triads either visually or aurally for recall, with interpolated shadowing of visually or aurally presented digits. Furthermore, he found a release from proactive inhibition in shifting from a block of visually presented triads to a block of aurally presented triads, and vice versa, as well as in shifting from a block of triads presented in one modality to a block presented in both (but not vice versa).

Thus, despite the finding of acoustic or verbal encoding in a variety of tasks with a variety of stimuli, there do appear to be situations in which acoustic or verbal encoding into memory does not seem evident. Where nonverbal material is presented that lacks readily accessible verbal labels or efficient, unambiguous decoding rules, encoding is likely to be nonverbal. Even with such easily verbalized material as letters, evidence for verbal encoding is not found in a task entailing visual search. Finally, when the 
same material is presented visually rather than aurally, it seems to be encoded differently, that is, at least partly visually, as it is more subject to visual sources of interference.

The present experiment attempts to demonstrate that the same material can be encoded differently depending on how the $S$ expects to use it. The stimuli employed, schematic faces with well-learned names, have two equivalent manifestations, pictorial and verbal, and thus they can, in principle, be encoded in either of two modalities, pictorial or verbal. The task is similar to that of Posner and Keele (1967). A single face or name is presented and taken away, followed by a second one. The $S$ is instructed to respond "same" if the two stimuli have the same name, and "different" otherwise. It is predicted that if the second stimulus is pictorial (verbal) and the $S$ has encoded the first stimulus pictorially (verbally), he will respond faster than if he has not encoded the first stimulus in the modality of the second.

Since the $S$ is paid only for correct answers, and for those in proportion to his speed, it is to his advantage to encode as expected, if he is able to. Trials are blocked by the modality of the second stimulus, with the assumption that Ss will encode the first stimulus appropriately. Since the reaction time to the second stimulus under appropriate encoding must be compared to that under inappropriate encoding, a small proportion (ca 21\%) of the second stimuli of each block type are in the inappropriate modality. The modality of the first stimulus, however, is constant within a block. Thus, there are four types of trial blocks. In two of the blocks, the second stimulus is predominantly pictorial, so that pictorial encoding is expected; of these, the first stimulus of one block is pictorial, while the first stimulus of the other is verbal. In the other two blocks, the second stimulus is predominantly verbal, which is expected to yield verbal encoding, while the first stimulus is verbal in one block and pictorial in the other.

There is a possibility that the predicted reaction time difference could arise from surprise due to the unexpected modality or from expectancy of a particular physical representation of the stimulus rather than from encoding in the expected modality. An additional control was included for these possibilities. After completing the experiment proper, the Ss performed for two additional sessions on the verbal-verbal type block. On $21 \%$ of the trials, the second stimuli were slanted verbal stimuli (instead of pictorial second stimuli). It might be argued that although the slanted names are a different physical representation from the upright names, they are, nevertheless, very similar. It seems difficult in principle, however, to construct comparable stimuli in the same modality that will be as different as equivalent stimuli in another modality. If the differences in reaction time are due primarily to surprise or expectation of a particular representation of a combination of both, stimulus pairs of the expected type should also be significantly faster than those of the unexpected type in the control condition. If they are not, then the encoding hypothesis is strongly supported.

\section{Subjects}

\section{METHOD}

The Ss were eight right-handed female undergraduates at the University of Michigan. They were paid a flat fee plus whatever they earned during the experimental sessions. Earnings averaged about $\$ 1.85$ per session.

\section{Experimental Stimuli}

The stimuli were $2 \times 2$ black-on-white slides, consisting of a face or a name that on projection subtended a visual angle of approximately $1 \mathrm{deg} 30 \mathrm{~min}$. There were eight schematic faces, forming a product set of three attributes, each with two levels: face shape-fat or narrow; eyes-filled or unfilled; mouth-smiling
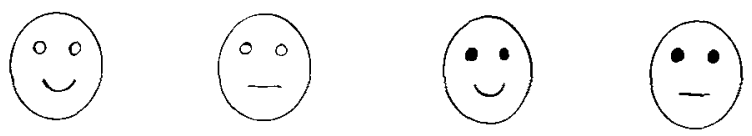

GOMO

DILI

GILI

DOMO
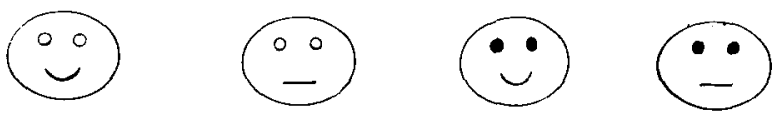

DOLO

GIM I

DIM I

GOLO

or unsmiling (see Fig. 1). The names were constructed in a formally identical manner: the first consonant was $/ \mathrm{d} /$ or $/ \mathrm{g} /$; the repeated vowel was /i/ (as in "dig") or $/ 0 /$ (as in "home"); the second consonant was $/ 1 /$ or $/ \mathrm{m} /$ (Fig. 1). Pictorial (verbal) distance can thereby be defined as the number of differing attributes in the pictorial (verbal) representation. Thus, in each representation, for every stimulus, there were three stimuli of Distance 1, three of Distance 2, and one stimulus of Distance 3. The names and faces were paired via a one-to-one mapping, constructed in order to maximize the negative correlation between the pictorial and verbal distances. Distances of 3 on one modality yield distances of 1 on the other modality, distances of 2 on one modality yield distances of 1 or 2 on the other modality, and distances of 1 on one modality yield distances of 2 or 3 on the other modality. Thus, $6 / 7$ of all possible pairs of stimuli can be classified as closer pictorially or verbally, depending on whether the distance between them is smaller in the pictorial or verbal representation.

\section{Training}

There were four 1 -h individual training sessions. In the first session, the faces were shown and named; it was pointed out to the $S$ that since there was no system relating facial to verbal characteristics, the best way to learn the names of the faces was to form an association for each pair. Ten random orders of each face with its name were projected for $10 \mathrm{sec}$ per slide. Then the faces were displayed without their names and the $S$ asked to supply the names. Once the $S$ could do this with almost no errors (this took half or more of the session), the names were displayed and the $S$ was asked to point to the appropriate face in the circular display of all eight faces on a sheet of paper. There were 15 different arrangements of faces on sheets of paper and the $S$ switched sheets every 20 or so trials to prevent learning of positions of faces. The Ss were asked to get a "clear visual image of the face" from the name before searching for the face in the array.

In the second and third training sessions, 80 trials of naming faces out loud alternated with 80 trials of pointing to the face with the projected name, for a total of 320 trials on each task on each day. Speed was encouraged in both tasks, as accuracy was nearly $100 \%$.

This routine was repeated on the fourth training day, except that the tasks were self-paced (the $S$ advanced the slide projector), the naming of faces was silent, as was the finding of the face on the sheet of paper. Then the experimental task was explained to the $S$, and eight practice trials were given.

\section{Experimental Design}

There were four types of trial blocks, schematized below: 


\begin{tabular}{|c|c|c|}
\hline Block Type & First Stimulus & Second Stimulu \\
\hline 1 & Pictorial & $\begin{array}{l}\text { Pictorial } 79 \% \\
\text { Verbal } 21 \%\end{array}$ \\
\hline 11 & Verbal & $\begin{array}{l}\text { Pictorial } 79 \% \\
\text { Verbal } 21 \%\end{array}$ \\
\hline III & Pictorial & $\begin{array}{l}\text { Pictorial } 21 \% \\
\text { Verbal } 79 \%\end{array}$ \\
\hline IV & Verbal & $\begin{array}{l}\text { Pictorial 21\% } \\
\text { Verbal } 79 \%\end{array}$ \\
\hline
\end{tabular}

For Block Types I and II, pictorial encoding was expected, while for Types III and IV, verbal encoding was expected; in any one session, the Ss participated in blocks only of Types I and II or only Types III and IV.

There were eight random orders, subdivided into four blocks of 28 trials each, so that the probability that "same" was correct was one-half within both $79 \%$ (frequent) and $21 \%$ (infrequent) type trials and that every stimulus was paired equally of ten with every other stimulus within each order, and appeared equally often in every position over all orders. Each order was randomly assigned to one of the eight following conditions, defined by the sequence of trial block types:

$\begin{array}{lllll}\text { 1 } & \text { I } & \text { II } & \text { II } & \text { I } \\ 2 & \text { IV } & \text { III } & \text { IV } & \text { III } \\ 3 & \text { II } & \text { I } & \text { II } & \text { I } \\ 4 & \text { III } & \text { IV } & \text { IV } & \text { III } \\ 5 & \text { I } & \text { II } & \text { I } & \text { II } \\ 6 & \text { IV } & \text { III } & \text { III } & \text { IV } \\ 7 & \text { II } & \text { I } & \text { I } & \text { II } \\ 8 & \text { III } & \text { IV } & \text { III } & \text { IV }\end{array}$

Modality was randomly assigned to each stimulus of each order in accordance with the trial block conditions. Thus, within each order, the second stimulus was either predominantly verbal or predominantly pictorial, while the first stimulus was verbal for two blocks and pictorial for two blocks.

\section{Experimental Sessions}

The Ss performed individually, in each order successively, on separate days, with two Ss beginning with each of the first four orders. Each day's session was preceded by an explanation of which block types would appear that session and four practice trials for the first block type. Before the second block, there were four additional practice trials of that type. Each set of practice trials always contained a second stimulus of the infrequent modality. On a typical trial, the first stimulus was projected for $1 \mathrm{sec}$, followed automatically by a neutral-density grey slide for $1 \mathrm{sec}$, and then the second stimulus for $4 \mathrm{sec}$, which was more than adequate for the S's response. The $S$ responded by pressing a key with the index finger of one hand for "same" or with the index finger of the other hand for "different." For one of the pair of Ss beginning the experiment with each order the left key was designated "same"; for the other, the left key was designated "different." After the second stimulus, a second neutral-density grey slide with four horizontally arrayed asterisks appeared, during which time feedback was given. The $S$ then initiated the next trial by pressing a food pedal.

After every 14th trial, a break long enough to change slide trays was given. During this time, The $\mathrm{S}$ was told the dominant modalities of the nex 14 trials. The 112 trials of an entire session took about $30-35 \mathrm{~min}$.

The feedback to the $S$ was the number of points she had earned if she was correct; otherwise, she was told, when she did

not spontaneously say so herself, that she had made an error. The $S$ gained 5 points if her reaction time was at her previous day's mean, plus a point for every $50 \mathrm{msec}$ faster or minus a point for every 50 msec slower. She could receive no more than 10 and no fewer than 1 point for a correct response. Each point was worth $.2 \downarrow$ over the base rate of $\$ 1.00$ per session. The first session's scale was estimated from the practice trials of the last training session, but altered after the first block of trials if necessary. Each successive day's scale was estimated from the second half of the previous day's trials, except that the scale was not changed for the last two experimental sessions, nor was it changed after the reaction time worth 5 points got as low as $700 \mathrm{msec}$. During the control sessions the scale was again changed, if necessary.

\section{Control}

Each $S$, except S 3 and $S 4$, who did not return to the university in the fall, served as her own control. The Ss served in two 35-min sessions on separate days and were paid in the manner of the previous experimental sessions.

The stimuli were the name slides from the previous experimental sessions plus slides with the names printed in the same letter style and size, but in thicker letters slanted sharply to the right. Experimental Orders 4 and 6 were revised for the control sessions, so that in each of the four daily experimental blocks, both the first and second stimuli were names, and the second stimuli were slanted names on $21 \%$ of the trials (the same frequency with which a face would have appeared as the second stimulus in the experimental sessions). Within the two orders, each name appeared equally often within both the $79 \%$ and $21 \%$ trial ty pes. ${ }^{3}$ The faces were not used at all, and the slanted names never appeared as the first stimuli. The Ss whose right index finger operated the "same" key received Order A first; the others received Order B first, followed by Order A.

The Ss were familiarized with the slanted names at the beginning of each control session; each name was projected three times in each of its two forms. Four practice trials preceded each day's trials. The procedure was like that of the experimental sessions.

\section{Reaction Times: Experimental Sessions}

Table 1 displays the mean reaction times for each $S$ and over Ss, to frequent (trials where the expected or $79 \%$ second stimulus modality was presented) stimulus pairs categorized as to same or different, first half (first four sessions) or second half (second four sessions), first stimulus verbal or pictorial, and second stimulus verbal or pictorial. Table 2 contains the same information for infrequent (trials where the unexpected or $21 \%$ second stimulus modality was presented) stimulus pairs. There are approximately 44 values for each S's "frequent" mean and 12 values for each S's "infrequent" mean. The effect of frequency was assessed by a sign test for the 32 comparisons ( 8 sessions $x 4$ blocks) for each $S$. The number of violations of the hypothesis that reaction times to second stimuli of the expected modality are faster than to those of the unexpected modality for Ss 1 through 8 , in order, are: $4,0,1,2,1,1,2,1$. The sign test supports the hypothesis at the .001 level for each $S$. The average reaction time for frequent pairs was $705 \mathrm{msec}$ and the average reaction time for infrequent pairs was $873 \mathrm{msec}$. The effects of practice, same-different, first stimulus modality, and second stimulus modality were assessed by two four-way analyses of variance per $S$, one on reaction times to the dominant second stimulus modality and one on reaction times to the nondominant second stimulus modality. The results of these analyses of variance are displayed in Table 3 for the frequent second stimulus modality pairs and in Table 4 for the infrequent pairs. All Ss 
Table 1

Mean Correct Reaction Time for Each $S$ and Over Ss for Frequent Pairs by Same-Different, Part of Experimental Sessions, First Stimulus Modality, and Second Stimulus Modality

\begin{tabular}{lcccc}
\hline & \multicolumn{2}{c}{ 1st Stimulus Verbal } & \multicolumn{3}{c}{ 1st Stimulus Pictorial } \\
$\mathrm{S}$ & 2nd Verbal & 2nd Pictorial & 2nd Verbal & 2nd Pictorial \\
\hline Same & & \multicolumn{4}{c}{ First Half } \\
\hline 1 & .665 & .941 & .619 & .787 \\
2 & .737 & .725 & .690 & .788 \\
3 & .929 & .722 & .848 & .816 \\
4 & .728 & .779 & .758 & .728 \\
5 & .674 & .656 & .616 & .681 \\
6 & .682 & .752 & .651 & .742 \\
7 & .829 & .716 & .812 & .730 \\
8 & .702 & .637 & .648 & .603 \\
\hline $\bar{X}$ & .743 & .741 & .705 & .734 \\
\hline
\end{tabular}

\section{Different}

\begin{tabular}{lllll}
1 & .747 & .888 & .716 & .784 \\
2 & .754 & .814 & .711 & .797 \\
3 & .859 & .823 & .916 & .828 \\
4 & .809 & .856 & .852 & .800 \\
5 & .657 & .697 & .656 & .695 \\
6 & .712 & .802 & .733 & .775 \\
7 & .851 & .780 & .830 & .743 \\
8 & .702 & .662 & .676 & .640 \\
\hline
\end{tabular}

\begin{tabular}{lllll}
$\bar{X}$ & .761 & .790 & .761 & .758 \\
\hline Same & & & Second & Half \\
\hline 1 & .602 & .709 & .585 & .659 \\
2 & .670 & .657 & .665 & .673 \\
3 & .705 & .674 & .689 & .667 \\
4 & .690 & .736 & .720 & .699 \\
5 & .594 & .580 & .589 & .594 \\
6 & .639 & .606 & .600 & .610 \\
7 & .667 & .610 & .671 & .609 \\
8 & .585 & .559 & .572 & .564 \\
\hline $\bar{X}$ & .644 & .641 & .636 & .634 \\
\hline
\end{tabular}

\section{Different}

\begin{tabular}{lllll}
\hline 1 & .661 & .729 & .664 & .675 \\
2 & .704 & .749 & .721 & .689 \\
3 & .746 & .758 & .739 & .736 \\
4 & .745 & .762 & .742 & .740 \\
5 & .621 & .635 & .613 & .597 \\
6 & .693 & .686 & .692 & .703 \\
7 & .676 & .685 & .657 & .592 \\
8 & .617 & .609 & .616 & .592 \\
\hline $\bar{x}$ & .683 & .702 & .681 & .673 \\
\hline
\end{tabular}

show a statistically reliable practice effect, with an average reaction time in the first half of $841 \mathrm{msec}$, decreasing to $737 \mathrm{msec}$ in the second half. All Ss are significantly faster in saying "same" (685 msec) than in saying "different" (726 msec) for the frequent second-stimulus modality pairs, but this difference is notably not in evidence for the infrequent second-stimulus modality pairs. Beyond these statements, no other generalizations about effects and interactions of modalities and other factors can be advanced, although significant patterns are apparent within individuals.

\section{Reaction Times: Control Sessions}

The mean reaction times to the dominant second stimulus modality (verbal) and to the nondominant second stimulus modality (verbal slanted) for each $S$, along with the results of within- $S \mathrm{t}$ tests are displayed in Table 5. These differences, in contrast to the frequent-infrequent differences in the experi-
Table 2

Mean Correct Reaction Time for Each $S$ and Over Ss for Infrequent Pairs by Same-Different, Part of Experimental Sessions, First Stimulus Modality, and Second Stimulus Modality

\begin{tabular}{|c|c|c|c|c|}
\hline \multirow[b]{2}{*}{$\mathbf{S}$} & \multicolumn{2}{|c|}{ 1st Stimulus Verbal } & \multicolumn{2}{|c|}{ 1st Stimulus Pictorial } \\
\hline & 2nd Verbal & 2nd Pictorial & 2nd Verbal & 2nd Pictorial \\
\hline Same & \multicolumn{4}{|c|}{ First Half } \\
\hline $\begin{array}{l}1 \\
2 \\
3 \\
4 \\
5 \\
6 \\
7 \\
8\end{array}$ & $\begin{array}{r}.919 \\
1.023 \\
.917 \\
.982 \\
.759 \\
.923 \\
.915 \\
.725\end{array}$ & $\begin{array}{r}1.315 \\
.995 \\
1.309 \\
1.204 \\
.805 \\
.729 \\
.937 \\
1.013\end{array}$ & $\begin{array}{r}.866 \\
1.096 \\
.954 \\
.973 \\
.734 \\
.838 \\
1.008 \\
.656\end{array}$ & $\begin{array}{l}.847 \\
.920 \\
.915 \\
.981 \\
.702 \\
.771 \\
.951 \\
.798\end{array}$ \\
\hline$\underline{\overline{\mathbf{X}}}$ & .895 & 1.038 & .891 & .861 \\
\hline \multicolumn{5}{|c|}{ Different } \\
\hline $\begin{array}{l}1 \\
2 \\
3 \\
4 \\
5 \\
6 \\
7 \\
8\end{array}$ & $\begin{array}{r}1.010 \\
1.091 \\
1.001 \\
.839 \\
.755 \\
.846 \\
.916 \\
.751 \\
\end{array}$ & $\begin{array}{r}.965 \\
1.091 \\
1.285 \\
1.397 \\
.787 \\
.767 \\
1.026 \\
1.120\end{array}$ & $\begin{array}{r}.886 \\
1.084 \\
1.032 \\
.944 \\
.763 \\
.955 \\
1.192 \\
.786 \\
\end{array}$ & $\begin{array}{l}.820 \\
.893 \\
.991 \\
.884 \\
.733 \\
.856 \\
.943 \\
.830 \\
\end{array}$ \\
\hline$\overline{\mathbf{x}}$ & .901 & 1.055 & .955 & .869 \\
\hline Same & \multicolumn{4}{|c|}{ Second Half } \\
\hline $\begin{array}{l}1 \\
2 \\
3 \\
4 \\
5 \\
6 \\
7 \\
8\end{array}$ & $\begin{array}{l}.718 \\
.843 \\
.842 \\
.855 \\
.710 \\
.717 \\
.819 \\
.708 \\
\end{array}$ & $\begin{array}{r}.783 \\
.971 \\
.921 \\
1.015 \\
.648 \\
.713 \\
1.151 \\
.676 \\
\end{array}$ & $\begin{array}{l}.662 \\
.904 \\
.937 \\
.899 \\
.676 \\
.729 \\
.813 \\
.663 \\
\end{array}$ & $\begin{array}{l}.779 \\
.799 \\
.819 \\
.813 \\
.662 \\
.736 \\
.809 \\
.725 \\
\end{array}$ \\
\hline$\overline{\mathrm{x}}$ & .777 & .860 & .785 & .768 \\
\hline \multicolumn{5}{|c|}{ Different } \\
\hline $\begin{array}{l}1 \\
2 \\
3 \\
4 \\
5 \\
6 \\
7 \\
8\end{array}$ & $\begin{array}{l}.835 \\
.883 \\
.840 \\
.810 \\
.739 \\
.788 \\
.819 \\
.660 \\
\end{array}$ & $\begin{array}{r}.861 \\
1.054 \\
1.204 \\
1.009 \\
.718 \\
.770 \\
.918 \\
.856 \\
\end{array}$ & $\begin{array}{l}.821 \\
.881 \\
.886 \\
.869 \\
.728 \\
.824 \\
.912 \\
.708 \\
\end{array}$ & $\begin{array}{l}.720 \\
.835 \\
.891 \\
.754 \\
.684 \\
.822 \\
.729 \\
.673 \\
\end{array}$ \\
\hline$\overline{\mathrm{x}}$ & .797 & .924 & .829 & .764 \\
\hline
\end{tabular}

mental sessions, tend to be small. For the two Ss for whom there is a significant difference $(p<.05)$, these differences are in the direction opposite to that predicted by either a surprise or an expectation-of-particular-representation hypothesis.

All Ss were significantly faster $(p<.001$, t test) in responding to the frequent second stimulus modality in the two control sessions than in the comparable (first and second stimuli verbal) conditions in the last four experimental sessions. That this effect is not just a continuation of thepractice effect is evidenced by the fact that these differences were larger for five out of the six Ss than the differences between the two halves of the experiment, and larger by twice as much for four Ss.

\section{Reaction Times: "Different" Responses}

A detailed analysis of reaction times to correct "different" responses to the frequent second-stimulus modality pairs was performed. It will be recalled that for every $S$, "different" 
Table 3

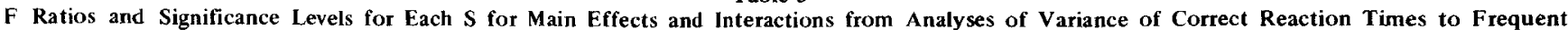
Second-Stimulus Modality Pairs

\begin{tabular}{|c|c|c|c|c|c|c|c|c|}
\hline Effect $N=44$ & S-1 & S-2 & $S-3$ & $S-4$ & S-5 & $S-6$ & S-7 & S-8 \\
\hline $\begin{array}{l}\text { A Same ys } \\
\text { Different }\end{array}$ & $\begin{array}{c}15.538 \\
* * \\
\end{array}$ & $\begin{array}{c}20.727 \\
* * \\
\end{array}$ & $\begin{array}{c}13.176 \\
* *\end{array}$ & $\begin{array}{c}39.329 \\
* *\end{array}$ & $\begin{array}{c}18.037 \\
* *\end{array}$ & $\begin{array}{c}87.663 \\
* *\end{array}$ & $\begin{array}{c}9.392 \\
* *\end{array}$ & $\begin{array}{c}20.603 \\
* *\end{array}$ \\
\hline $\begin{array}{l}\text { B Modality } \\
\text { Stimulus } 2 \\
\end{array}$ & $\begin{array}{c}147.045 \\
* *\end{array}$ & $\begin{array}{c}10.507 \\
* * \\
\end{array}$ & $\begin{array}{c}17.834 \\
* *\end{array}$ & .599 & $\begin{array}{c}6.981 \\
* *\end{array}$ & $\begin{array}{c}24.843 \\
* *\end{array}$ & $\begin{array}{c}37.715 \\
* *\end{array}$ & $\begin{array}{c}22.538 \\
* *\end{array}$ \\
\hline $\begin{array}{l}\text { C Modality } \\
\text { Stimulus } 1 \\
\end{array}$ & $\begin{array}{c}36.006 \\
* *\end{array}$ & 1.080 & .119 & .796 & 2.648 & 1.494 & 1.975 & $\begin{array}{c}9.255 \\
* *\end{array}$ \\
\hline $\begin{array}{l}\text { D 1st Half } \\
\text { vs 2nd Half }\end{array}$ & $\begin{array}{c}131.455 \\
* *\end{array}$ & $\begin{array}{c}43.667 \\
* \\
\end{array}$ & $\begin{array}{c}164.601 \\
* * \\
\end{array}$ & $\begin{array}{c}40.822 \\
* *\end{array}$ & $\begin{array}{c}132.333 \\
* *\end{array}$ & $\begin{array}{c}127.337 \\
* * \\
\end{array}$ & $\begin{array}{c}196.082 \\
* *\end{array}$ & $\begin{array}{c}108.282 \\
* * \\
\end{array}$ \\
\hline $\mathrm{AB}$ & $\begin{array}{c}20.199 \\
* *\end{array}$ & 1.153 & 2.306 & .250 & .741 & 0 & $\begin{array}{c}4.690 \\
*\end{array}$ & .487 \\
\hline$A C$ & 1.096 & 3.160 & 1.228 & .026 & .352 & 2.482 & 2.025 & .333 \\
\hline AD & .442 & .700 & $\begin{array}{c}4.834 \\
*\end{array}$ & $\begin{array}{c}5.812 \\
*\end{array}$ & .519 & $\begin{array}{l}5.012 \\
*\end{array}$ & 0 & 1.397 \\
\hline $\mathrm{BC}$ & $\begin{array}{c}12.769 \\
* *\end{array}$ & 1.233 & .632 & $\begin{array}{c}12.954 \\
* *\end{array}$ & 2.574 & .422 & .184 & .256 \\
\hline $\mathrm{BD}$ & $\begin{array}{c}27.000 \\
* * \\
\end{array}$ & $\begin{array}{c}9.020 \\
* * \\
\end{array}$ & $\begin{array}{c}10.415 \\
* *\end{array}$ & .118 & $\begin{array}{c}9.556 \\
* * \\
\end{array}$ & $\begin{array}{c}32.169 \\
* * \\
\end{array}$ & $\begin{array}{c}10.025 \\
* *\end{array}$ & $\begin{array}{c}5.077 \\
* \\
\end{array}$ \\
\hline $\mathrm{CD}$ & $\begin{array}{c}8.205 \\
* * \\
\end{array}$ & .027 & .029 & 0 & 0 & .253 & .044 & $\begin{array}{c}4.218 \\
*\end{array}$ \\
\hline $\mathrm{ABC}$ & .026 & $\begin{array}{c}6.053 \\
*\end{array}$ & $\begin{array}{c}5.741 \\
* \\
\end{array}$ & .164 & $\begin{array}{c}9.167 \\
* * \\
\end{array}$ & 2.976 & .506 & .833 \\
\hline $\mathrm{ABD}$ & 3.115 & .340 & 0 & .039 & .370 & 1.012 & 1.323 & .385 \\
\hline$A C D$ & .436 & .080 & 1.617 & .145 & 3.630 & .084 & 0 & .910 \\
\hline $\mathrm{BCD}$ & 1.417 & $\begin{array}{c}6.693 \\
* \\
\end{array}$ & .845 & 1.586 & $\begin{array}{c}4.500 \\
*\end{array}$ & 2.458 & 0 & .154 \\
\hline$A B C D$ & .596 & .040 & 3.347 & .803 & .537 & .639 & .272 & .103 \\
\hline
\end{tabular}

$* * p<.01$

$* p<.05$

responses were significantly slower than "same." Reaction times to stimulus pairs differing on one relevant attribute were compared to those differing on more than one relevant attribute for each $\mathrm{S}$, collapsing across modalities and session (Table 6). Pairs differing by three attributes were grouped with pairs differing by two attributes because the number of cases of the former was so low. For instance, reaction times for sessions in which the second stimulus was predominantly verbal and the stimulus pairs differed by only one letter were grouped with reaction times from sessions where the second stimulus was predominantly pictorial and the stimulus pairs differed by only one facial feature. Likewise, verbal pairs in which the second stimulus differed by two or three letters were grouped with pictorial pairs in which the second stimulus differed by two or three facial features. Ambiguous stimuli, those differing by two verbal as well as two pictorial attributes, were omitted from the analysis. All Ss were faster in saying "different" when the stimulus pairs differed by more than one attribute. Furthermore, this difference was significant $(p<.05, t$ test) for all but two Ss. Inspection of the data of Table 7 reveals that this effect depends neither on the particular modality, verbal or pictorial, nor on whether the first and second stimuli were of the same modality. The same result was obtained for infrequent second-stimulus modality pairs. When the stimuli differed by only one attribute in the presented (as opposed to expected) modality of the second stimulus, all Ss took longer to respond than when the stimuli differed by two or three attributes, by $39 \mathrm{msec}$ on the average. This is approximately the same average difference as was obtained with frequent second-stimulus modality pairs ( $38 \mathrm{msec}$ ).

The "different" responses to frequent second-stimulus modality pairs differing by one attribute were subjected to further analysis, to assess systematic effects of particular attributes. Mean reaction times to "different" responses where the second stimulus was verbal categorized by the locus of differences are displayed in Table 8 , along with the comparable results for stimuli differing by one pictorial attribute. For pairs differing verbally, all Ss except one responded faster when the difference was in the vowels. There was no consistency over Ss in speed of response to pairs differing by the first or second consonant. It should be pointed out that the vowels were not only repeated, but were perhaps less acoustically confusing than either set of consonants. In the case of pictorial attributes, six out of eight Ss were slowest when the faces differed by the mouth, and either face shape or eyes seemed to facilitate the "different" judgment equally. For the remaining two Ss, "different" responses were slowest when the faces differed by the eyes, next slowest when they differed by the mouth.

\section{Errors}

The error rate, averaged over Ss and experimental sessions was $5 \%$. The rates per $\mathrm{S}$, from $\mathrm{S} 1$ to $\mathrm{S} 8$, were: $3 \%, 3 \%, 7 \%, 4 \%, 4 \%$, $9 \%, 7 \%, 6 \%$. There was no systematic change in the error rate 
Table 4

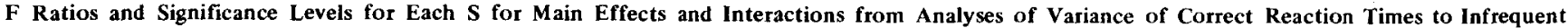
Second-Stimulus Modality Pairs

\begin{tabular}{|c|c|c|c|c|c|c|c|c|}
\hline Effect $N=12$ & S-1 & S-2 & $S-3$ & S-4 & S-5 & $S-6$ & S-7 & S-8 \\
\hline $\begin{array}{l}\text { A Same vs } \\
\text { Different }\end{array}$ & .010 & .582 & 4.470 & .948 & 3.189 & $\begin{array}{c}13.117 \\
* *\end{array}$ & .057 & 3.654 \\
\hline $\begin{array}{l}\text { B Modality } \\
\text { Stimulus } 2\end{array}$ & 1.439 & .520 & $\begin{array}{c}14.304 \\
* *\end{array}$ & $\begin{array}{c}16.236 \\
* *\end{array}$ & 1.104 & $\begin{array}{c}12.234 \\
* *\end{array}$ & .100 & $\begin{array}{c}22.520 \\
* *\end{array}$ \\
\hline $\begin{array}{l}\text { C Modality } \\
\text { Stimulus } 1\end{array}$ & $\begin{array}{c}10.486 \\
* *\end{array}$ & 2.472 & $\begin{array}{c}13.400 \\
* *\end{array}$ & $\begin{array}{c}20.398 \\
* *\end{array}$ & 4.066 & 4.508 & .412 & $\begin{array}{l}9.441 \\
*\end{array}$ \\
\hline $\begin{array}{l}\text { D 1st Half } \\
\text { vs 2nd Half }\end{array}$ & $\begin{array}{c}21.698 \\
* *\end{array}$ & $\begin{array}{l}8.912 \\
*\end{array}$ & $\begin{array}{c}19.014 \\
* * \\
\end{array}$ & $\begin{array}{c}28.690 \\
* * \\
\end{array}$ & $\begin{array}{c}15.868 \\
* *\end{array}$ & $\begin{array}{c}20.188 \\
* *\end{array}$ & $\begin{array}{c}17.065 \\
* *\end{array}$ & $\begin{array}{c}21.480 \\
* *\end{array}$ \\
\hline AB & $\begin{array}{l}5.714 \\
*\end{array}$ & .109 & 1.508 & 1.593 & 0 & .203 & $\begin{array}{l}5.385 \\
*\end{array}$ & .272 \\
\hline $\mathrm{AC}$ & .251 & .831 & .456 & .956 & .245 & $\begin{array}{l}5.070 \\
*\end{array}$ & 2.334 & .253 \\
\hline AD & 3.243 & .001 & .130 & .082 & 1.255 & 1.250 & 4.671 & .593 \\
\hline $\mathrm{BC}$ & 2.695 & $\begin{array}{l}5.301 \\
*\end{array}$ & $\begin{array}{c}28.846 \\
* *\end{array}$ & $\begin{array}{c}39.915 \\
* *\end{array}$ & .953 & 1.063 & $\begin{array}{c}22.612 \\
* *\end{array}$ & $\begin{array}{l}7.772 \\
*\end{array}$ \\
\hline BD & .261 & 2.494 & 1.188 & $\begin{array}{c}6.690 \\
*\end{array}$ & 1.745 & $\begin{array}{c}10.516 \\
* *\end{array}$ & 3.526 & $\begin{array}{c}8.978 \\
*\end{array}$ \\
\hline $\mathrm{CD}$ & 3.429 & .131 & 2.020 & 1.703 & .840 & .070 & $\begin{array}{c}11.218 \\
* *\end{array}$ & 3.522 \\
\hline $\mathrm{ABC}$ & .476 & .007 & .049 & 4.585 & .226 & 1.180 & 1.051 & $\begin{array}{c}5.385 \\
* \\
\end{array}$ \\
\hline ABD & .546 & .067 & 4.497 & 1.376 & .038 & .672 & 1.943 & .461 \\
\hline$A C D$ & 1.255 & .075 & 2.114 & .387 & .802 & 2.070 & .555 & .596 \\
\hline $\mathrm{BCD}$ & 1.339 & .104 & .658 & 1.549 & 1.925 & .398 & .668 & 2.348 \\
\hline $\mathrm{ABCD}$ & 3.393 & .029 & 1.219 & 2.338 & .547 & 1.367 & 2.270 & .087 \\
\hline
\end{tabular}

$* * p<.01$

$* p<.05$

over sessions for any $S$, nor was there any dependence on modality. All Ss made proportionally more errors on stimulus pairs where the second stimulus modality was infrequent rather than frequent. For each $S$, errors tended to be faster $(p<.05$, sign test within-S) than correct responses of the same trial block. Ss 1, 5, and 6 made considerably more incorrect "same" responses, while Ss $2,3,4,7$, and 8 committed considerably more incorrect "different" responses; these effects balance each other in the group average.

In the control sessions, the error rate decreased for each $\mathrm{S}$ (S 1, $2 \%$; S 2, 2\%; S 5, 3\%; S 6, 5\%; S 7, 5\%; S 8, 4\%). The proportion of errors to pairs of infrequent second stimulus modality was not higher than the proportion expected by chance for all Ss but one.

Table 5

Mean Reaction Times for Correct Responses to Frequent and Infrequent Second-Stimulus Modality Pairs by $\mathbf{S}$ for Control Sessions

\begin{tabular}{cccccc}
\hline Subject & Frequent & $\mathrm{N}$ & Infrequent & $\mathrm{N}$ & $\begin{array}{c}\text { Probability } \\
\text { (t-test) }\end{array}$ \\
\hline 1 & .474 & 170 & .460 & 48 & n.s. \\
2 & .540 & 172 & .547 & 47 & n.s. \\
5 & .494 & 171 & .499 & 46 & n.s. \\
6 & .590 & 170 & .527 & 44 & p $<.05$ \\
7 & .586 & 167 & .559 & 46 & p $<.05$ \\
8 & .482 & 165 & .487 & 48 & n.s. \\
\hline
\end{tabular}

\section{Encoding Hypothesis}

\section{DISCUSSION}

This experiment provides strong evidence that Ss' encoding strategies can be manipulated by the response expected from them. When the majority of the second stimuli were pictorial, Ss responded faster to pictorial than to verbal stimuli, irrespective of the modality of the first stimulus. Likewise, whe the majority of the second stimuli were verbal, Ss responded faster to verbal than to pictorial second stimuli, irrespective of the first stimulus modality. This result cannot easily be attributed to either surprise or to expectation of a different physical representation, rather than expectation of a different modality. The same Ss, in control sessions, responded at least as fast to second stimuli that were

Table 6

Mean Reaction Times for Correct "Different" Responses to Frequent Second-Stimulus Modality Pairs Differing by One vs Two or Three Revelant Attributes with Associated t-Test Probabilities for Each S

\begin{tabular}{cccccc}
\hline Subject & 1 Attribute & $\mathrm{N}$ & $\begin{array}{c}2 \text { or } 3 \\
\text { Attributes }\end{array}$ & $\mathrm{N}$ & $\begin{array}{c}\text { Probability } \\
\text { (t-test) }\end{array}$ \\
\hline 1 & .758 & 127 & .711 & 153 & $\mathrm{p}<.025$ \\
2 & .765 & 135 & .726 & 152 & $\mathrm{p}<.01$ \\
3 & .821 & 128 & .791 & 146 & $\mathrm{p}<.10$ \\
4 & .834 & 129 & .757 & 151 & $\mathrm{p}<.01$ \\
5 & .669 & 131 & .636 & 153 & $\mathrm{p}<.01$ \\
6 & .747 & 117 & .714 & 149 & $\mathrm{p}<.01$ \\
7 & .750 & 129 & .734 & 140 & n.s. \\
8 & .657 & 133 & .627 & 149 & p $<.01$ \\
\hline
\end{tabular}


Table 7

Mean Reaction Times for Each $S$ and Over Ss for Correct "Different" Responses to Frequent Second-Stimulus Modality Piars Differing by One vs Two and Three Attributes by First and Second-Stimulus Modalities

\begin{tabular}{|c|c|c|c|c|c|c|c|c|}
\hline \multirow{2}{*}{$\begin{array}{l}\text { Stimulus 1- } \\
\text { Stimulus } 2 \\
\text { Number of } \\
\text { Attributes }\end{array}$} & \multirow{2}{*}{\multicolumn{2}{|c|}{$\begin{array}{l}\begin{array}{l}\text { Verbal- } \\
\text { Verbal }\end{array} \\
2 \& 3\end{array}$}} & \multicolumn{2}{|c|}{$\begin{array}{l}\text { Pictorial- } \\
\text { Verbal }\end{array}$} & \multicolumn{2}{|c|}{$\begin{array}{l}\text { Pictorial- } \\
\text { Pictorial }\end{array}$} & \multicolumn{2}{|c|}{$\begin{array}{l}\text { Verbal- } \\
\text { Pictorial }\end{array}$} \\
\hline & & & 1 & $2 \& 3$ & 1 & $2 \& 3$ & 1 & $2 \& 3$ \\
\hline S-1 & .726 & .686 & .706 & .698 & .761 & .703 & .836 & .762 \\
\hline $\mathrm{S}-2$ & .758 & .700 & .727 & .709 & .793 & .707 & .783 & .797 \\
\hline$S-3$ & 817 & .790 & .849 & .829 & .801 & .780 & .817 & .763 \\
\hline S-4 & .805 & .761 & .880 & .75 & .805 & .73 & .848 & .777 \\
\hline S-5 & .644 & .647 & .651 & .625 & .675 & .630 & .703 & .643 \\
\hline$S-6$ & .710 & .697 & .720 & .70 & .787 & .726 & .768 & .728 \\
\hline S-7 & .759 & .783 & .744 & .74 & .716 & .70 & .776 & .707 \\
\hline S-8 & .691 & .639 & .667 & .635 & 617 & .605 & .644 & .633 \\
\hline $\mathrm{X}$ & .739 & .713 & .743 & .713 & .744 & .699 & .772 & .726 \\
\hline
\end{tabular}

infrequent and physically different, though of the same modality. Furthermore, Ss responded faster to verbal-verbal pairs in the control than in the experimental sessions, indicating that merely removing the possibility of pictorial encoding decreased processing time.

Error data corroborate this hypothesis. Errors were faster on the whole than correct responses, suggesting that the Ss erred when they stopped processing and responded too soon (Egeth \& Smith, 1967). In the experimental sessions, error rate to pairs where the second stimulus was of the less frequent modality was considerably higher than expected, indicating that Ss were less likely to complete processing for these types of stimuli where more processing was necessary. Such a disparity in error rates to frequent and infrequent second-stimulus modality pairs did not occur in the control sessions, so that it, too, is not attributable to the effects of frequency or to expectation of a particular physical representation.

That Ss encode differently depending on the expected modality of the second stimulus is further supported by reaction times to stimulus pairs differing by one as opposed to more than one attribute. When the pairs differed by more than one attribute along the modality of the second stimulus, Ss responded faster than when the pairs differed by only one attribute, irrespective of the modality of the first stimulus. Thus the Ss were faster in saying "different" when the stimuli were less similar, where similarity is defined in terms of the number of attributes in common in the encoding (second stimulus) modality. Recall that pairs that are similar along one modality are different along the other and that the above effect was obtained regardless of the modality of the first stimulus. Consequently, this effect alone provides strong evidence that the first stimuli were encoded in the modality of the second. It is difficult to see how any theory that does not assume that encoding modalities are switched could account for this finding. It might be noted that the observation that reaction time decreased with more different attributes along the modality of the second stimulus would have been difficult to make without the construction of special stimuli in which the verbal and pictorial patterns of similarity are known and negatively correlated.

Thus, Ss take on the average $156 \mathrm{msec}$ longer to make a "same" or "different" judgment when the second stimulus is not presented in the expected modality. Presumably, Ss use this extra time to translate the stimulus in memory to the modality of the second stimulus or vice versa, so that a judgment may be made about a pair of stimuli. The finding that "different" responses to pairs of the infrequent second stimulus modality are faster when the stimuli differ by more than one attribute along the prese ited second stimulus modality indicates that the stimulus in mesory is reencoded to the modality of the stimulus on the screen, $t$ ather than vice versa.

There is some reason to believe that these results may depend on appropriate choice of interstimulus interval, which $n$ this study was $1 \mathrm{sec}$. Had the stimuli been simultaneous, or c'oser in time, there probably would have been residual effects of the modality of the first stimulus. Had the stimuli been spaced further apart in time, Ss might have had difficulty retaining the stimuli in one modality or the other. Posner and Keele (1967) did find an increased tendency toward verbal (name) rat xer than visual encoding of letters over a 1.5 -sec interstimulus interval in a similar task, but their Ss did not know whether they would have to make a physical (visual or pictorial) or a name (verbal) match, so that these results reflect preferences rather than capacities.

Modality preferences were also expressed by the present Ss. "Preference" here is understood to mean relative ease of encoding in or responding to one modality over the other, as inferred from reaction time advantages, rather than, say, "liking" the pictorial display better than the verbal. Interesting patterns of preferences emerge from the individual reaction time protocols. $S 8$, for instance, always performed faster when the first and second stimuli were pictorial, while $S 4$ consistently responded faster when the second stimulus modality was the same as the first, showing no independent modality preferences. While such patterns may arouse endless speculation, little of a general nature can be said about them.

\section{"Same"."Different" Judgments}

The advantage in reaction time of responses to the expected second stimulus modality over the unexpected second stimulus modality was not the only marked difference in reaction time

Table 8

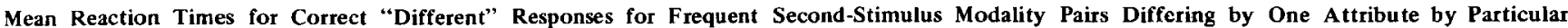
Attribute for Each $S$

\begin{tabular}{|c|c|c|c|c|c|c|c|c|c|c|c|c|}
\hline & & & \multicolumn{6}{|c|}{ Verbal } & \multicolumn{4}{|c|}{ Pictorial } \\
\hline & \multicolumn{2}{|c|}{$\begin{array}{c}\text { I'irst } \\
\text { Consonant }\end{array}$} & \multicolumn{2}{|c|}{ Vowel } & \multicolumn{2}{|c|}{$\begin{array}{c}\text { Second } \\
\text { Consonant }\end{array}$} & \multicolumn{2}{|c|}{ Mouth } & \multicolumn{2}{|c|}{ Eyes } & \multicolumn{2}{|c|}{$\begin{array}{c}\text { Face } \\
\text { Shape }\end{array}$} \\
\hline & $\mathrm{RT}$ & $N$ & RT & $\mathrm{N}$ & RT & $\mathbf{N}$ & RT & $\mathbf{N}$ & RT & $\mathbf{N}$ & RT & $\mathbf{N}$ \\
\hline S-1 & .728 & 22 & .687 & 25 & .747 & 18 & .792 & 18 & .767 & 20 & .769 & 24 \\
\hline S-2 & .761 & 22 & .708 & 23 & .752 & 21 & .817 & 20 & .834 & 23 & .722 & 25 \\
\hline$S-3$ & .876 & 21 & .794 & 25 & .670 & 17 & .862 & 19 & .780 & 22 & .795 & 23 \\
\hline S-4 & .886 & 23 & .798 & 22 & .834 & 24 & .837 & 20 & .842 & 12 & .813 & 23 \\
\hline S-5 & .632 & 21 & .626 & 26 & .701 & 17 & .715 & 20 & .671 & 22 & .687 & 25 \\
\hline S-6 & .712 & 19 & .696 & 23 & .749 & 14 & .803 & 15 & .770 & 20 & .768 & 26 \\
\hline S-7 & .800 & 23 & .674 & 24 & .728 & 18 & .808 & 17 & .714 & 22 & .728 & 24 \\
\hline S-8 & .683 & 23 & .670 & 26 & .691 & 22 & .668 & 16 & .612 & 23 & .625 & 22 \\
\hline
\end{tabular}


consistent across Ss. All Ss took longer to respond "different" than to respond "same" to pairs of the expected second stimulus modality. A "compare-and-check" process, in which the "same" judgment is processed in one stage, and the "different" judgment in two, can account for this finding. In the "compare" stage, the stimulus in memory is compared to the stimulus on the screen by template matching, or by an exhaustive check of attributes. Were the process self-terminating, "different" responses would be shorter than "same." If inspection reveals that the stimuli are identical (name identity; not necessarily physical), the $\mathrm{S}$ responds "same." If inspection does not reveal identity, however, the $S$ apparently does not automatically respond "different," al though he has the necessary information to do so. Rather, he appears to reexamine the stimulus pairs as if to discover where the difference lies, a "check" process that is easier to rationalize if template matching rather than serial inspection has occurred at the first stage. It takes him longer to find a difference if members of the pair differ only on one attribute. Furthermore, he seems to search for a difference by a serial self-terminating check of attributes: in the case of faces, first checking the eyes or face shape, and then the mouth; in the case of words, first checking the vowels, and then the consonants. This finding for words indicates that while the search or check may be serial, it is not linear with the natural order of the letters. This "compare-and-check" analysis of the processing of "same"-."different" judgments is consistent with much data collected by other Es. In experiments where one item is in memory and one in display, and $S$ is asked whether the display includes the contents of memory, "no" responses are equivalent to "different" and "yes" responses to "same." In this task, Sternberg (1966, 1967), using digits, and Nickerson (1966), using letters, found "no" responses to be significantly slower than "yes" responses. In another experiment, Nickerson (1965) found that "different" responses persisted in being slower than "same" responses to pairs of letters over 22 days of practice. Using stimuli that could differ by one, two, or three attributes, Nickerson (1967) found faster "different" responses where stimuli differed on more attributes, and still faster "same" responses, for at least sequential stimulus presentation. While data from the many experiments of Posner and Mitchell (1967) are not internally consistent, these investigators usually found "different" responses to be slower than "same," for name as well as physical identity. Lindsay and Lindsay (1966) used a task where there were essentially two "same" responses, both of which were faster than the one "different" response. Responses were to the appearance of one of 32 geometric figures, formed from five attributes, each with two levels. To 30 of the figures, $S$ responded by pressing his index finger; to the 31 st, by pressing his middle finger; to the remaining figure, by pressing his ring finger. Stimuli were presented so that responses were equally probable. Not only were reaction times faster to the two stimuli with unique responses, but also reaction times to the remaining stimuli varied with the values of particular attributes, as if Ss were scanning these serially. To explain their results, these investigators propose a process similar to that discussed here.

Another type of model that might account for these results asserts that the "same"-"different" judgment is made in a self-terminating fashion, yielding faster reaction times for stimuli differing on fewer attributes, but that the "different" or "no" response takes longer to make than the "same" or "yes" response. This is not likely to be a motor effect, as half the Ss used their dominant hands for "same," and half used their nondominant hands. This explanation is not entirely satisfactory, since it provides no rationale for the difference in response time.

It must be recognized that several studies report no difference in reaction time to "same" and "different" responses or faster reaction time to "different" responses (Bindra, Donderi, \&
Nishisato, 1968; Bindra, Williams, \& Wise, 1965; Corballis, Lieberman, \& Bindra, 1968; Nishisato \& Wise, 1967; Sekular \& Abrams, 1968). As Bindra et al (1968) point out, such a result is usually obtained where the stimuli are not readily codable, that is, where categorization depends on a reference stimulus. With stimuli not easily codable, there is little reason to expect the "check" stage of the process described earlier, so that these data are not necessarily inconsistent with the "compare-and-check" hypothesis.

How a person encodes his experiences into memory, what he selects to store, and how he chooses to store it, can determine the type of error he makes, the sort of material he remembers, as well as the speed with which he processes certain types of information. Evidence, of the third variety, has been presented that Ss can adopt different encoding strategies, either pictorial or verbal, depending on whether the incoming information, a face or a name, is to be used in a pictorial or verbal comparison. Thus, not only is the manner of encoding information into memory flexible, but it can be manipulated by anticipation of the use to which the information is to be put.

\section{REFERENCES}

ADAMS, J. A., \& DIJKSTRA, S. Short-term me mory for motor responses. Journal of Experimental Psychology, 1966, 71, 314-318.

BADDELEY, A. D. Semantic and acoustic similarity in short-term memory. Nature, 1964, 204, $1116-1117$.

BADDELEY, A. D. Short-term memory for word sequences as a function of acoustic, semantic and formal similarity. Quarterly Journal of Experimental Psychology, 1966a, 18, 362-365.

BADDELEY, A. D. The influence of acoustic and semantic similarity on long-term memory for word-sequences. Quarterly Joumal of Experimental Psychology, 1966b, 18, 302-309.

BINDRA, D., DONDERI, D. C., \& NISHISATO, S. Decision latencies of "same" and "different" judgments. Perception \& Psychophysics, 1968, $3,121-130$.

BINDRA, D., WILLIAMS, J. A., \& WISE, J. S. Judgments of sameness and difference: Experiments on decision time. Science, 1965, 150, 1625-1627.

BROWN, R. W., \& LENNEBERG, E.H. A study in language and cognition. Journal of Abnormal \& Social Psychology, 1954, 49, 454-462.

CONRAD, R. Acoustic confusions and memory span for words. Nature, 1963, 197, 1029-1030.

CONRAD, R. Acoustic confusions in immediate memory. British Journal of Psychology, 1964, 55, 75-84.

CONRAD, R., BADDELEY, A. D., \& HULL, A. J. Rate of presentation and the acoustic similarity effect on short-term memory. Psychonomic Science, 1966, 5, 233-234.

CONRAD, R., \& HULL, A. J. Information, acoustic confusion and memory span. British Journal of Psychology, 1964, 55, 429-432.

CORBALLIS, M. C., LIEBERMAN, W., \& BINDRA, D. Discriminability and central intermittancy in same-different judgments. Quarterly Journal of Experimental Psychology, 1968, 20, 51-61.

DALE, H. C. A., \& GREGORY, M. Evidence of semantic coding in short-term memory. Psychonomic Science, 1966, 5, 75-76.

EGETH, H., \& SMITH, E. On the nature of errors in a choice reaction task. Psychonomic Science, 1967, 8, 345-346.

GIBSON, E. J., \& YONAS, A. A developmental study of the effects of visual and auditory interference on a visual scanning task. Psychonomic Science, 1966a, 5, 163-164.

GIBSON, E. J., \& YONAS, A. A developmental study of visual search behavior. Perception \& Psychophysics, 1966b, 1, 169-171.

GLANZER, M., \& CLARK, W. H. Accuracy of perceptual recall: An analysis of organization. Journal of Verbal Learning \& Verbal Behavior, 1963a, 1, 289-299.

GLANZER, M., \& CLARK, W. H. The verbal loop hypothesis: Binary numbers. Joumal of Verbal Learning \& Verbal Behavior, 1963b, 2, 301-309.

GLUCKSBERG, S.. FISHER, D. F., \& MONTY, R. A. Brief vi sual memory as a function of visual and acoustic confusability. Proceedings, 75th Annual Convention, American Psychological Association, 1965, 55-56.

KAPLAN, G. A., YONAS, A., \& SHURCLIFF, A. Visual and acoustic confusability in a visual search task. Perception \& Psychophysics, 1966, $1,172-174$.

LANTZ, D., \& STEFFLRE, V. Language and cognition revisited. Journal of Abnormal \& Social Psychology, 1964, 69, 472-481.

LINDSAY, R. K., \& LINDSAY, J. M. Reaction time and serial vs. parallel 
information processing. Journal of Experimental Psychology, 1966, 71 , 294-303.

MARGRAINE:, S. A. Short-term memory as a function of input modality. Quarterly Journal of Experimental Psy chology, 1967, 12, 109-114.

NICKERSON, R. S. Response times for "same"-"different" judgments. Perceptual \& Motor Skills, 1965, 20, 15-18.

NICKERSON, R. S, Response times with a memory-dependent task. Journal of Experimental Psy chology, 1966, 72, 761-769.

NICKERSON, R. S. "Same-different" response times with multi-attribute stimulus differences. Perceptual \& Motor Skills, 1967, 24, 543-554.

NISHISATO, S., \& WISE, J. S. Relative probability, interstimulus interval, and speed of the same-different judgment. Psychonomic Science, 1967, $7,59-60$.

POSNER, M. I. Characteristics of visual and kinesthetic memory codes. Journal of Experimental Psy chology, 1967,67, 103-107.

POSNI:R, M. I., \& KEELE, S. W. Decay of visual information from a single letter. Science, 1967, 158, 137-139.

POSNER, M. 1., \& KONICK, A. F. Short-term retention of visual and kinesthetic information. Organizational Behavior \& Human Performance, 1966, 1, 71-86.

POSNER, M. I., \& MITCHELL, R. F. Chronometric analysis of classification. Psychological Review, 1967, 74, 392-409.

RUDOV. M. H. Dimensionality in human information storage. Joumal of Experimental Psychology, 1966, 71, 273-281.

SEKULAR, R, W., \& ABRAMS, M. Visual sameness: A choice time analysis of pattern recognition processes. Journal of Experimental Psychology, 1968, 77, 232-238.

SPERLING, G. Successive approximations to a model for short-term memory. Acta Psychologica, 1967, 27, 285-292.

STERNBI:RG, S. High-speed scanning in human memory. Science, 1966, $153,652-654$.

STERNBERG, S. Scanning a persisting visual image versus a memorized list. Paper presented at the annual meeting of the Eastern Psychological Association, Boston, Massachusetts, April 1967.

TURVEY, M. I. Phonemic coding and the visual preperceptual system. Journal of Experimental Psychology, 1967, 74, 289-293.

TVERSKY, B. Pictorial and verbal encoding in short-term memory.
Technical Report No. 10, Human Performance Center, Department of Psychology, University of Michigan, October 1968.

VAN DE GEER, J. P., \& I'RIDJA, N. H. Studies in codability: II. Identification and recognition of facial expression. Report No. E002-60, 1960, Psychological Institute, State University of Leyden, The Netherlands.

WICKELGREN, W. A. Acoustic similarity and intrusion errors in short-term memory. Journal of Experimental Psychology, 1965a, 70, 102-108.

WICKELGREN, W. A. Acoustic similarity and retroactive interference in short-term memory. Journal of Verbal Learning \& Verbal Behavior, $1965 b, 4,53-61$.

WICKELGREN, W. A. Short-term memory for phonemically similar lists. American Journal of Psychology, 1965c, 78, 567-575.

WICKELGREN, W. A. Phonemic similarity and interference in short-term memory for single letters. Journal of Experimental Psychology, 1966a, $71,396-405$.

WICKELGREN, W. A. Short-term recognition memory for single letters and phonemic similarity of retro-active interference. Quarterly Journal of Experimental Psychology, 1966b, 181, 55-63.

\section{NOTES}

1. This work is based on a doctoral dissertation completed at the Human Performance Center of the Department of Psychology, The University of Michigan. The author would like to thank her chairman, Professor Arthur W. Melton, and the members of her committee, Professor David H. Krantz and Dr. Robert Bjork, for their helpful suggestions. The research was supported by the Advanoed Research Projects Agency, Behavioral Sciences Command and Control Research, under Order No.461, Amendments 3 and 5 , and monitored by the Behavioral Sciences Division, Air Force Office of Scientific Research, under Contract No. AF 49(638)-1736.

2. Address: Department of Psychology, The Hebrew University of Jerusalem, Jerusalem, Israel.

3. Due to an error in making the slides, one of the names (GOMO) never appeared in its slanted form.

(Accepted for publication March 17, 1969.) 